\title{
QUANTO MAIS PEIXE, MELHOR: SOBRE A IMPORTÂNCIA DA PESCA PARA
} OS MBYÁ-GUARANI

THE MORE FISH THE BETTER: ABOUT THE IMPORTANCE OF FISHING FOR THE MBYÁ-GUARANI

Mártin César Tempass

Como citar este artigo:

TEMPASS, Mártin César. Quanto mais peixe, melhor: sobre a importância da pesca para os Mbyá-Guarani. In: Cadernos do Lepaarq, v. XVI, n.32., p. 169-179, Jul-Dez. 2019. 


\title{
Quanto mais peixe, melhor: sobre a importância da pesca para os Mbyá-Guarania
}

\author{
Mártin César Tempass ${ }^{\mathrm{b}}$
}

Resumo: O presente artigo resulta de quinze anos de diferentes pesquisas etnográficas realizadas em aldeias Mbyá-Guarani do estado do Rio Grande do Sul. O objetivo é analisar os aspectos práticos e simbólicos das pescarias e do consumo de peixes por este grupo indígena. Em um primeiro momento, analisaremos a relação da etnia com as águas e a importância atribuída aos peixes para a construção de corpos e almas perfeitos. Depois serão apresentadas as modalidades e técnicas empregadas pelos Mbyá-Guarani na prática pesqueira. Por fim, serão discutidas as regras que tornam sustentáveis as pescarias dos Mbyá-Guarani. .

\begin{abstract}
This article is the result of fifteen years of different ethnographic research carried out in Mbyá-Guarani villages in the state of Rio Grande do Sul. The objective is to analyze the practical and symbolic aspects of fisheries and fish consumption for this indigenous group. In a first moment, we will analyze the relation of the ethnicity with the waters and the importance attributed to the fishes for the construction of perfect bodies and souls. Then the modalities and techniques used by the Mbyá-Guarani in fishing practice will be presented. Finally, we will analyze the rules that make sustainable the fisheries of the Mbyá-Guarani.
\end{abstract}

\section{Palavras Chave:}

Pesca; Mbyá-Guarani; Cosmologia; Alimentação

\section{Keywords:}

Fishing; Mbyá-Guarani; Cosmology; Food

\footnotetext{
${ }^{a} \mathrm{O}$ presente artigo é fruto de recortes e fusões de outros textos meus, que direta ou indiretamente abordavam a questão da pesca e o consumo de pescados pelos Mbyá-Guarani. Versões parciais destes trabalhos foram apresentadas na REA/ABANNE de 2015, XI SAB-Sul de 2018 e Maritimidades

2018. Agradeço aos debatedores dos GTs pelas valiosas contribuições ao texto que agora reapresento.
}

b Mestre e Doutor em Antropologia Social pela Universidade Federal do Rio Grande do Sul (UFRGS), Brasil. Professor do Bacharelado em Arqueologia da Universidade Federal do Rio Grande (FURG), Brasil. E-mail: potz_51@yahoo.com.br 


\section{INTRODUÇÃO}

Os Mbyá-Guarani, que constituem uma das parcialidades étnicas dos grupos de língua Guarani, possuem suas aldeias distribuídas sobre um vasto território que abrange parcelas significativas dos territórios de Brasil, Argentina, Paraguai e Uruguai. Esse amplo território é habitado pelos Mbyá-Guarani de forma descontinua, como se suas aldeias (tekoá) fossem "ilhas" estrategicamente localizadas em contextos de muita biodiversidade ${ }^{1}$. Ocorre que os Mbyá-Guarani, desde tempos imemoriais, erguem as suas tekoá em lugares "eleitos" que, segundo a cosmologia do grupo, são os mais indicados para a sua reprodução física e cultural (LADEIRA e MATTA, 2004; TEMPASS, 2012).

Idealmente, os lugares "eleitos” devem apresentar uma configuração ambiental bastante específica, que geralmente corresponde ao que no Brasil chamamos de Mata Atlântica e que na Argentina e Paraguai é conhecida como Floresta Paranaense (ENRIZ, 2010). Trata-se de um ambiente riquíssimo em biodiversidade que fornece aos Mbyá-Guarani o que precisam para sobreviver, tanto em recursos materiais quanto em aspectos simbólicos. E um dos principais quesitos para a configuração ideal desses locais "escolhidos" é a presença de "águas" - fontes, córregos, arroios, rios, lagos e/ou o Oceano Atlântico. Dessa forma, podemos considerar os grupos Mbyá-Guarani como coletivos costeiros, que tem na pesca e no consumo de pescado um importante alimento para os seus corpos e suas almas.

A pesca é universal para todos os povos ameríndios (SUSNIK, 1990). Os peixes (pirá) são um dos alimentos mais apreciados pelos Mbyá-Guarani. E eles também são os alimentos que têm a forma de obtenção mais apreciada. Todos adoram uma pescaria. Trata-se de uma atividade despreocupada pois, diferente da caça onde os animais e seus espíritos podem oferecer perigos aos Mbyá-Guarani, as pescarias não apresentam grandes riscos (embora exijam igual respeito, como veremos a seguir). E também, pensando a alimentação como construtora de corpos e almas, o preparo e consumo de pescados requer menos cuidados em comparação com o consumo de carnes de outros animais.

Os Mbyá-Guarani estão na Terra atual $(\text { Yvy Pyau })^{2}$ passando por uma espécie de prova, para atingir a condição de divindades. Para isso eles precisam primeiro alcançar o aguyje, que é a completude, a perfeição do ser (H. CLASTRES, 1978; CADOGAN, 1997). O aguyje é a perfeição dos seus conjuntos corpo e alma, posto que cada uma dessas partes depende da outra. E o aguyje é alcançado com muita sabedoria e vivência, alicerçadas por um respeito a uma série de regras estabelecidas de acordo com os fundamentos cosmológicos (PISSOLATO, 2007). Dentre essas regras podemos destacar as regras alimentares e as regras de reciprocidade entre os diferentes tipos de seres que habitam o cosmos Mbyá-Guarani (TEMPASS, 2012). Em função dessas regras, a prática pesqueira e o consumo de pescados apresentam algumas singularidades entre os Mbyá-Guarani.

Essas singularidades também estão relacionadas com a crença dos Mbyá-Guarani na dualidade de sua(s) alma(s) ${ }^{3}$. Porém, esse caráter dual não se resume apenas a(s) alma(s) dos Mbyá-Guarani, mas também aos seus corpos. Ocorre que entre

\footnotetext{
${ }^{1}$ Atualmente, a localização em ambientes muito biodiversos muitas vezes se limita ao plano ideal, posto que na prática grande parte das aldeias do grupo teve a sua biodiversidade destruída pela sociedade envolvente.

2 Os Mbyá-Guarani nos falam da existência, em um passado mítico, de uma Primeira Terra (Yvy Tenondé), que foi destruída em um dilúvio (iporum). Foram as divindades que destruíram essa Primeira Terra, por estarem descontentes com parte dos seres que a habitavam. Os Mbyá-Guarani sobreviveram a essa destruição, por serem os “escolhidos dos deuses”. Uma Segunda Terra (Yvy Pyau) foi criada para os Mbyá-Guarani viverem (CADOGAN, 1997; H. CLASTRES, 1978).

${ }^{3}$ Isso é consenso na etnologia Guarani. Mas, se por um lado todos os autores concordam com o caráter dual da alma Mbyá-Guarani, não há consenso sobre o número de almas que eles possuem. Esse número varia de autor para autor, ou de informante para informante. Em campo também obtive informações desencontradas, sendo que o número de almas variou entre uma e quatro. Não me preocupei muito em desvendar esta questão, posto que, independente do número de almas declaradas, sempre há ao menos uma alma ou uma porção de alma de origem sagrada e outra de origem telúrica.
}

TEMPASS, Mártin César. Quanto mais peixe, melhor: sobre a importância da pesca para os Mbyá-Guarani. In: Cadernos do Lepaarq, v. XVI, n.32., p. 169-179, Jul-Dez. 2019 
os Mbyá-Guarani não se pode isolar os domínios da natureza, da sociedade ou da sobrenatureza (TEMPASS, 2011). O mesmo se aplica na relação corpo e alma(s). Corpo e alma(s) são construídos e operados em conjunto. Um define o outro. O aguyje (a perfeição do ser) só é alcançado se corpo $E$ alma(s) estiverem "perfeitos".

Os Mbyá-Guarani costumam se referir às suas almas simplesmente como "a alma", talvez por uma alegoria didática para facilitar a compreensão dos juruá, ou talvez porque efetivamente há apenas uma alma, mas com duas porções distintas, uma telúrica e outra sagrada. E ambas as almas - ou ambas porções da alma - nunca podem ser analisadas separadamente, posto que operam em um mesmo veículo, o corpo. Neste caso, o corpo pode ser comparado a uma gangorra: quando a alma sagrada "sobe" a alma telúrica "baixa". Não há condições para que ambas "subam" ao mesmo tempo.

O corpo é o veículo da(s) alma(s), é o seu habitat. Mas, como tudo é “caminho” para os Mbyá-Guarani, é possível afirmar que a(s) alma(s) “circula(m)” pelo corpo dos indivíduos desta etnia. E, de fato, se "caminhar” é manter-se vivo, como apontou Pissolato (2007), a(s) alma(s) precisa(m) “circular” pelo corpo para também se manterem vivas. Mas, cada diferente alma, ou porção de alma, possui o seu "caminho". Ocorre que o corpo, por associação, também é dividido em porções telúricas e sagradas. Agrupando as diferentes partes do corpo humano podemos estabelecer que o conjunto "carne e sangue" é o "caminho" da(s) alma(s) telúrica(s), enquanto que o "esqueleto" é o "caminho" da(s) alma(s) sagrada(s).

A circulação da alma sagrada é que mantém o esqueleto e, consequentemente, os Mbyá-Guarani eretos. A alma sagrada é a "alma-palavra" (FERREIRA, 2001; CLASTRES, 1978), somente "eretos” os Mbyá-Guarani podem pronunciar palavras. É ela que mantém “erguido o fluir do dizer" (CADOGAN, 1997). O esqueleto e a fala são condições da alma sagrada. Tanto o falar quanto o andar ereto são distintivos dos Mbyá-Guarani frente aos animais. O Mbyá-Guarani que não puder falar também não poderá andar, e vice-versa. A fala circula pelo esqueleto ereto. Qualquer um dos sintomas, não andar e/ou falar, é um sinal que a alma sagrada está abandonando o corpo Mbyá-Guarani, ou está sendo vencido pela alma telúrica. Isso para os Mbyá-Guarani significa a morte. Ou, significa adentrar o domínio da animalidade ${ }^{4}$, posto que não falar e/ou andar é característico dos animais.

Os alimentos tradicionais favorecem a construção de um corpo sagrado. Diariamente, a cada ingestão alimentar, corpos e almas são construídos e reconstruídos. É um processo longo em que cada dia se "caminha” bem pouco. Os alimentos “tradicionais" dos Mbyá-Guarani são chamados de orérembiú, que significa "nossa comida” (TEMPASS, 2005). A orérembiú é sagrada, pois foi especialmente criada pelos deuses para que os Mbyá-Guarani sobrevivam e passem pela prova de viver nesse mundo imperfeito. Consumir a orérembiú significa alimentar as porções sagradas de seus corpos-almas. Mas, dentre os alimentos sagrados existem alguns que são mais eficientes para alcançar o aguyje. Essa classificação é bastante complexa (ver TEMPASS, 2012), mas, grosso modo, podemos afirmar que o consumo de vegetais é mais indicado que o consumo de carnes - ou menos perigoso, se considerarmos o risco sempre presente deles adentrarem o domínio da animalidade. Os peixes são uma exceção a essa regra.

É como se os peixes constituíssem uma categoria a parte, separada do reino animal. Mas, se todos os peixes são bem vistos para o consumo, algumas espécies são especialmente recomendadas para a perfeição de corpos e almas. Para isso temse como regra que as espécies que melhor se alimentam também servirão de melhores alimentos para os Mbyá-Guarani. Um exemplo disso, citado pelos próprios Mbyá-Guarani, é o pirapé, o peixe “mais limpo de todos”, pois ele come apenas o limo das pedras do fundo dos rios.

\footnotetext{
4 A animalidade é grande temor de qualquer Mbyá-Guarani. Ocorre que em sua cosmologia eles se localizam entre a natureza e a sobrenatureza. Entre os animais e os deuses. Se forem bem-sucedidos em suas vidas, os Mbyá-Guarani se tornam deuses. Mas, em sentido contrário, se não viverem corretamente, eles serão transformados em animais. E, como para o aguyje, as regras alimentares são as que mais pesam para esta punição. E os meus interlocutores sabem de vários casos de Mbyá-Guarani que foram transformados em animais (TEMPASS, 2005 e 2012).
} 
pirapé, ele é peixe muito boa. Ele é considerado sagrado porque ele não come muita coisa. Pra nós é sagrado porque criou deus, mas ele tem uma comida só. Por isso ele é sagrado. Ele não tem dente, só boca. Alimento dele é só pedra, ele lambe só pedra. Outra coisa não come. Por isso é sagrado. [...]. Se tem uma comida certa, tem saúde. Mas se come várias coisas, não é alimento sagrado. Cada bicho sagrado tem um alimento só. Por isso o alimento é muito bom. A carne é muito saudável (MBYÁ-GUARANI apud POZZEBON, 2008, p. 56).

Como já observado, as tekoá dos Mbyá-Guarani são como “ilhas” distribuídas sobre um vasto território, encravadas "entre" outras sociedades. Atualmente elas figuram, principalmente, entre as nucleações da sociedade envolvente. O interessante é que essas "ilhas” Mbyá-Guarani sempre se localizaram - e ainda se localizam - próximas aos cursos de água. Os Mbyá-Guarani eram hábeis canoeiros no passado e, mesmo no caso dos deslocamentos por terra, se orientavam baseados no percurso dos rios. Tanto que é que a expansão territorial dos grupos Guarani se deu seguindo os grandes rios (SOUZA, 2008).

As embarcações tradicionais dos Mbyá-Guarani eram feitas com a casca (ou a cortiça) do cedro, que, tirada de forma intacta, tinha suas extremidades moldadas a fim de conferir o formato de canoa. Essas canoas eram de tamanhos variados, mas as maiores podiam transportar até vinte e cinco pessoas (PALERMO, HOYOS e CHIAPPE, 2006). Atualmente, a navegação é rara entre os Mbyá-Guarani, mas para eles contínua sendo impensável uma tekoá que não seja cortada ou tangenciada por um curso d'água, sem um lugar para pescar. Também são muito importantes as "vertentes” de água nas matas próximas às casas dos Mbyá-Guarani. A água “corrida” (que para eles é contrário de água parada ${ }^{5}$ ) é sagrada, é fonte de saúde e juventude. Para tanto, é costume dos Mbyá-Guarani lavar o rosto com a água “corrida” fria todos os dias logo após acordar. Inclusive no mais frio do inverno.

Segundo Bartomeu Meliá (1986 e 1989) uma tekoá baseia-se no complexo casas-roças-matas, três espaços que se interligam e se completam, inclusive no que tange a obtenção e preparação dos alimentos Mbyá-Guarani. Porém, como sugeri em um trabalho anterior (TEMPASS, 2012), dada a importância que as águas têm para este grupo deveríamos pensar as tekoá como um complexo de "águas"-matas-roças-casas. Isso porque, como me afirmaram várias vezes os meus interlocutores Mbyá-Guarani, não existe tekoá sem "boas águas"”.

Assim, a pesca é um dos assuntos preferidos dos Mbyá-Guarani. Eles têm muitas histórias de pescador. São muitas as técnicas empregadas pelos Mbyá-Guarani na pescaria, desde a captura dos peixes com o simples emprego das mãos, até a construção de complicadas obras de engenharia que são as armadilhas para peixes (pari). As formas mais simples de pescar podem ser realizadas individualmente, mas como a atividade de pesca é uma "festa" para os Mbyá-Guarani, quanto mais indivíduos participarem, melhor. A forma mais elementar de capturar peixes é simplesmente agarrá-los com as mãos. Ocorre que alguns peixes, como o cascudo, por exemplo, se deslocam até as águas rasas e transparentes das margens dos rios onde

\footnotetext{
5 A água parada é considerada água "morta". Além de não favorecer em nada, ainda pode conter espíritos perigosos ou servir de veículo para a transmissão de "feitiços" (Cf. TEMPASS, 2012). Por isso no início dos anos 2000 alguns Mbyá-Guarani mais velhos se opuseram à instalação de caixas d'água e canos nas aldeias.

6 Atualmente, em função da desenfreada expansão da sociedade envolvente, os Mbyá-Guarani estão impossibilitados de acessar a maior parte do seu território ancestral. Muitas das suas terras sagradas e eleitas encontram-se desmatadas e/ou em posse de brancos (juruá), empresas ou reservas ecológicas. Isso faz com que muitos grupos desta parcialidade étnica tenham que viver em acampamentos de beira de estrada. Mas, esses acampamentos sempre estão localizados em áreas adjacentes ou muito próximas das terras tradicionalmente eleitas pelos Mbyá-Guarani. E, dessa forma, também estão localizados perto das fontes e cursos d'água que são importantes para o grupo. Curiosamente, muitas vezes os Mbyá-Guarani não podem acessar as suas terras, mas conseguem acessar as suas águas, posto que normalmente os arroios, os rios e os lagos não constituem propriedades privadas.
} 
se alimentam do "limo" de algumas pedras. Então Os Mbyá-Guarani ficam vigiando as margens e quando avistam um peixe simplesmente o recolhem. Embora não envolva o uso de nenhum equipamento, esta técnica de pescaria é considerada de difícil execução pelos Mbyá-Guarani, exigindo agilidade.

Junto as margens os Mbyá-Guarani também se valem do arco e flecha, quando os peixes estão fora do alcance de suas mãos. São empregadas flechas com pontas especialmente trabalhadas com micro engastes para "fisgar" bem o peixe. E para que o peixe atingido não "fuja” com a flecha, ou, já morto, seja levado pela correnteza, eles amarram delgados barbantes na extremidade contrária à ponta das flechas. Esta amarração muitas vezes atrapalha a pontaria, exigindo dos pescadores uma dose extra de habilidade no manuseio do equipamento. As crianças Mbyá-Guarani gostam muito desta modalidade de pescaria e desde pequenas já povoam margens de rios e riachos brincando e aprendendo a pescar. É curioso que, diferentemente da maioria das "conversas de pescador", onde o peixe maior sempre é o mais difícil de capturar, na pescaria com o arco e flecha o peixe menor é o alvo mais difícil. E o mais complicado é que o peixe não está onde ele é visto, em função do fenômeno de refração da luz na água. Assim, a pescaria com arco e flecha envolve cálculos complexos.

A pesca “com a mão" ou com flechas é praticada somente pelos indivíduos masculinos. Já a pesca com anzóis pode ser praticada por todos. Os Mbyá-Guarani, que hoje se valem dos anzóis dos juruá (não índios), no passado confeccionavam rústicos anzóis de pedras ou ossos ${ }^{7}$. Hoje também são empregadas linhas de náilon, no lugar das antigas cordoalhas feitas de fibras vegetais. A adoção destes dois utensílios, segundo os Mbyá-Guarani, não afetou a tradicionalidade da pescaria. Os peixes fisgados com os anzóis niquelados dos juruá, continuam sendo obtidos de forma tradicional.

No que tange a parte prática da pescaria com anzóis não é preciso tecer maiores comentários, posto que ela é desenvolvida de forma similar à da sociedade envolvente. Só que a pescaria dos Mbyá-Guarani é mais simples no que diz respeito aos equipamentos. Uma linha e um anzol são mais que suficientes. Eles acham muito engraçados os pescadores juruá que se valem de carretilhas, alicates para "desfisgar” os peixes, luvas, iscas artificiais, etc. Para os Mbyá-Guarani, o uso de uma série de equipamentos na pescaria apenas atesta a pouca prática do pescador.

As três modalidades descritas acima são classificadas pelos Mbyá-Guarani como "aquelas que pegam um peixe por vez”. Já as outras duas formas de pescaria, com plantas ictiotóxicas e com armadilhas, capturam dezenas, centenas ou até milhares de peixes por empreitada. Embora muito mais rentáveis, estas duas formas de pescaria possuem alto grau de dificuldade na execução porque envolve o trabalho de um grupo numeroso de pessoas e porque devem ser realizadas em um momento preciso do nível das águas. Isso faz com que elas sejam praticadas com pouca frequência. Mas, quando são realizadas ocorre uma "festa" em toda tekoá.

São três os “venenos” ictiotóxicos empregados pelos Mbyá-Guarani na pesca, extraídos das seguintes plantas: timbó, iraporá e ywuiraró. O iraporá tem efeito muito fraco, sendo que para dar resultado os Mbyá-Guarani precisam "tirar muita casca" da planta. O ywuiraró é bastante forte, mas é de difícil localização e manejo. Já o timbó é o melhor de todos os “venenos" para a pesca, é fácil de ser encontrado e fácil de ser extraído. Segundo os Mbyá-Guarani, o timbó penetra nos peixes pelos olhos, fazendo com que boiem como mortos por cerca de trinta minutos. Mas, eles não estão mortos, pois passado esse tempo eles voltam a "viver" como antes ${ }^{8}$.

\footnotetext{
7 Palermo, Hoyos e Chiappe (2006) e Colombre (2008) trabalhando com os Guarani em geral, afirmam que eles usavam também anzóis feitos de madeira e se valiam de insetos como iscas. O abandono dos anzóis tradicionais é muito antigo, tanto que nenhum Mbyá-Guarani usou ou viu um destes anzóis. Ninguém nem conhece alguém que os tenham usado, até mesmo entre os seus parentes da Argentina ou Paraguai, terras onde, segundos os meus interlocutores, em termos de caça e pesca tudo é possível.

${ }^{8}$ Alguns Mbyá-Guarani mais jovens não sabiam desta possibilidade dos peixes “voltarem a viver”, posto que nas condições atuais eles estão precisando retirar da água todo peixe possível.
}

TEMPASS, Mártin César. Quanto mais peixe, melhor: sobre a importância da pesca para os Mbyá-Guarani. In: Cadernos do Lepaarq, v. XVI, n.32., p. 169-179, Jul-Dez. 2019 
A pesca com timbó é feita em riachos ou pequenos rios, de pouca correnteza. O nível do curso d'água não pode estar muito alto, pois seria necessário usar muito timbó e a coleta dos peixes boiando seria difícil pela profundidade da água. Também não é usado timbó em rios com um nível de água muito baixo, pois a quantidade de peixe neste caso é muito pouca, não valendo a pena realizar a pescaria. E, mesmo assim, em alguns casos os Mbyá-Guarani precisam seccionar o curso d'água com um cercado bem fechado com folhas da palmeira pindó. O timbó é cortado em pedaços de cerca de trinta centímetros. Na margem do rio, sobre uma pedra semi-submersa os Mbyá-Guarani maceram os pedaços de timbó com auxílio de um outro pedaço de madeira. Da maceração resulta uma espuma, que é o próprio "veneno". Dependendo da quantidade de peixes almejados e do tamanho do rio, essa maceração do timbó pode ser realizada em diversos pontos, para melhorar a distribuição do produto na água.

Como já mencionado, a pesca com timbó envolve um grande número de participantes. Logo ao clarear o dia um grupo de Mbyá-Guarani se embrenha nas matas para coletar o timbó. Outros indivíduos vão fazendo os cercados no curso d’água, caso seja necessário. Depois começam a macerar o timbó, atividade que pode variar de trinta minutos a uma hora e meia. Por fim - o ponto alto da pescaria - os Mbyá-Guarani ganham as águas com seus balaios para coletar os peixes ${ }^{9}$. O mais interessante é que, não sendo muito adeptos da conservação dos alimentos, todo peixe obtido é imediatamente preparado, marcando o final da pescaria com uma grande festa.

A pesca com armadilhas (pari) também necessita de condições ideais do nível d'água. Mas diferentemente da pesca com timbó, a pesca com pari precisa de uma forte correnteza no riacho ou pequeno rio. É a correnteza que leva o peixe para a armadilha. Seccionando o curso d'água os Mbyá-Guarani erguem um complicado cercamento que represa parcialmente a água. Neste cercamento há uma única abertura que conduz os peixes "para o seco", sendo então facilmente recolhidos com as mãos. Nas palavras do Mbyá-Guarani Adorfo,

A boca tem que ficar [fora] da água, da correnteza. E depois termina lá fundo. Aquela correnteza termina lá. E quando o peixe vem ali, vai rápido, vai no seco lá na ponta ... Não sai mais. $\mathrm{Na}$ Argentina pegava muito ... Peixe grande, [piramatã], traíra de cinco quilos. Era ... Aquela traíra vem rápida e pula lá e já fica no seco. Menor bota de volta. Não machuca. Larga. Larga lá atrás [da armadilha] (Seu Adorfo, entrevista em 09/07/2005).

Os pari são preferencialmente armados nos meses de março e abril, quando ocorre uma melhor equação entre o volume das águas e a quantidade de peixes, sem comprometer o período de reprodução destes.

Nas pescarias maiores, ou de vários dias, toda a comunidade (homens, mulheres e crianças) se deslocam até a beira dos rios, estabelecendo lá um "acampamento de pesca”. Um Mbyá-Guarani comentou que estes acampamentos são como “férias" para os Mbyá-Guarani. Então, todos participam de forma direta ou indireta da pescaria.

Em campo os Mbyá-Guarani me informaram que em algumas tekoá atuais eles usam redes para pescar, mas foram categóricos em afirmar que isso é uma introdução recente, posto que não conseguem mais fazer armadilhas e pescar com "venenos" de forma satisfatória. Ou seja: os meus interlocutores não consideram a pesca com redes como tradicional dos Mbyá-Guarani. Na bibliografia consultada não há consenso sobre este ponto. Alguns afirmam que tradicionalmente os MbyáGuarani usavam redes para pescar, outros dizem que não usam.

Os Mbyá-Guarani pescam e consomem todo e qualquer tipo de peixe. Inclusive de qualquer tamanho. Quando

\footnotetext{
9 Mulheres grávidas e os seus maridos não devem entrar na água porque eles irão cortar o efeito do "veneno" (MARTINEZ-CROVETTO, 1968).

TEMPASS, Mártin César. Quanto mais peixe, melhor: sobre a importância da pesca para os Mbyá-Guarani. In: Cadernos do Lepaarq, v. XVI, n.32., p. 169-179, Jul-Dez. 2019
} 
perguntados sobre qual o peixe preferido, eles simplesmente respondem: "peixe". "Peixe é peixe". Ou, "é tudo peixe". Eles gostam de todos os peixes e nos seus discursos sobre pesca (nas suas "histórias de pescador") raramente mencionam alguma espécie em específico. Eles simplesmente pescam peixes e consomem peixes. Mas, no meu diário de campo tenho registros de pesca e consumo dos seguintes peixes: jundiá, traíra, cará, branca, cascudo, joana e lambari. Esse último tem importância lúdica, posto que a sua captura deixa a pescaria com crianças mais divertida. Lembro de algumas vezes em que insisti um pouco mais na conversa sobre as diferentes espécies de peixes. Aí destacaram o pirapé (já mencionado acima), pelas suas propriedades benéficas para a construção de corpos-almas. Também destacaram os jundiás, por serem peixes bonitos. E as traíras, pela sua força. Insistindo na questão do paladar, certa vez perguntei a dois Mbyá-Guarani sobre que peixe mais gostavam... o primeiro me respondeu "ensopado" e o segundo "assado".

Podemos dizer que as atividades pesqueiras desenvolvidas pelos Mbyá-Guarani são altamente sustentáveis. E isso em função da sua visão de mundo, por seguirem os preceitos do seu sistema xamãnico-cosmológico. Os grupos ameríndios, em geral, não adotam/definem limites rígidos entre as esferas da natureza e da cultura. Isso significa que animais e plantas também são vistos como sujeitos sociais (DESCOLA, 1998). Assim, em comparação com a sociedade envolvente, a distinção entre humanos e alimentos (ou entre humanos e animais e plantas) é minimizada. Reduzida apenas a uma questão corporal. Pois, da perspectiva dos ameríndios, não existe o multiculturalismo, mas sim o multinaturalismo. Para os povos ameríndios a cultura é universal e a natureza é particular. Todos os seres possuem os mesmos espíritos, apenas se distinguem pela diferente corporalidade. Em outras palavras, na "modernidade ocidental" a presença ou ausência do espírito é o distinguidor entre os diferentes seres. Entre os ameríndios, ao contrário, é o corpo que é o distinguidor (VIVEIROS DE CASTRO, 2002).

Assim, é possível trocar e/ou negociar com os animais e com os espíritos e/ou donos dos animais. Decorrente dessa visão inúmeros grupos indígenas das terras baixas da América do Sul creem em um ser ${ }^{10}$ denominado de o "dono da floresta", "el dueño del monte", "el dueño de los animales" ou ainda "el Señor de los animales" conforme as grafias consagradas pelos inúmeros autores de língua espanhola que se debruçaram sobre o tema. $\mathrm{O}$ "dueño del monte" é um ser sobrenatural que estabelece as regras para o uso dos recursos naturais que os humanos devem respeitar. Esse ser também é o responsável por impor punições aos humanos que não respeitarem essas regras de uso da natureza.

Pastor Arenas (2003) observa que no "Gran Chaco" todos os povos acreditam na existência dos "donos" de plantas e animais. E também nos donos dos ambientes, como pântanos, bosques, rios, planícies, etc. "A estos "dueños" se deberá agradar y en ningún caso contrariarlos; debe buscarse sus favores y dar cumplimiento a un conjunto de normas preestabelecidas para obtener benefícios en las actividades productivas" (ARENAS, 2003, p. 64). O mesmo autor destaca que estes donos também são chamados de chefes, pais, patrões, etc. E que ao "senhor da floresta" estão subordinados outros "senhores" mais específicos. Por exemplo, subordinado ao "senhor da floresta" existe o "senhor dos felinos", e subordinado a este encontramse os donos de cada felino específico. Para estes últimos é que os povos do "Gran Chaco" devem pedir permissão antes de caçar, coletar e pescar.

Ainda segundo Arenas (2003), os xamãs possuem vínculo direto com esses donos e seu principal papel é intermediar as relações entre os caçadores/pescadores/coletores com os seres que controlam o acesso aos alimentos. Ou seja, o xamã providencia a permissão. Mas, mesmo com a permissão, ainda há uma série de regras que precisam ser respeitadas. Por exemplo,

\footnotetext{
10 Também presente no imaginário popular de inúmeras sociedades mais distanciadas dos grandes centros urbanos. Por exemplo, a crença no "Señor de los animales" também é observada entre a população rural da Argentina, conforme informa Catalina Saugy de Kliauga (1984), sobretudo nas regiões do Paraná Médio e de Entre Rios.
}

TEMPASS, Mártin César. Quanto mais peixe, melhor: sobre a importância da pesca para os Mbyá-Guarani. In: Cadernos do Lepaarq, v. XVI, n.32., p. 169-179, Jul-Dez. 2019 
Los tobas mencionan la vigencia del pensamiento antiguo de no hacer mal uso de la colecta de mieles y larvas. Esto se expresa en no desecharlos o tirarlos al fuego por causas que no se justifiquen. Si ocurriera la transgresión, el Dueño o Padre (le 'ta) se encoleriza y castiga; éste consiste en que el o los involucrados no encuentre más colmenas y también hace que la persona se pierda en el monte (ARENAS, 2003, p. 294).

Entre os Mbyá-Guarani também voga a ideia exposta acima, mas em uma versão mais complexa. Ocorre que, para os Mbyá-Guarani, não existe um único “dono” da natureza, mas sim milhares, que são os já, os espíritos donos de cada elemento "natural". Cada animal tem o seu já. Cada planta também. Idem para o ar, a água, a terra, as rochas, etc. É essa multiplicidade de "donos" que cimenta a interdependência dos seres de todos os domínios do cosmos Mbyá-Guarani.

Branislava Susnik (1990) observou para os grupos Guarani em geral que as regras de caça são impostas por "conceitos mágico-religiosos"11 e que os caçadores para terem êxito dependem muito dos "donos dos animais". Estes castigam todo o Guarani que matar e não comer a sua presa.

Os Mbyá-Guarani, antes de se aventurarem nas caçadas, precisam realizar uma série de rituais, que servem de pedido de permissão aos já. Caso os ritos sejam corretamente executados, os já, satisfeitos, fornecerão animais para serem caçados pelos Mbyá-Guarani. Se algum Mbyá-Guarani caçar algum animal sem os devidos cuidados rituais, o já dono desse animal irá se zangar e castigará o caçador e, muito provavelmente, também toda a comunidade ${ }^{12}$. O castigo pode ser desde o simples não fornecimento de animais até a morte dos caçadores, que geralmente são causados por ataques de animais.

Se a tarefa da caça é, na maioria das vezes, feita de forma individual, os trabalhos rituais para proporcionar a caça são sempre coletivos, envolvendo toda a comunidade que se beneficiará dos alimentos obtidos. Mas, os Mbyá-Guarani nunca caçam mais do podem consumir. Não existe desperdício nesta parcialidade étnica. Não consumir um animal abatido seria como desperdiçar o trabalho e a boa vontade dos já. E, da mesma forma, caçar e consumir exclusivamente (ou simplesmente de forma desequilibrada) um determinado animal significa sobrecarregar esse já, em detrimento dos outros. Isso também causa a irá dos já, e vale para todos os alimentos. Assim, por essas concepções cosmológicas, a dieta dos Mbyá-Guarani é bastante variada.

A relação dos Mbyá-Guarani com os animais e plantas e com os seus já é uma relação de tipo social, como já observado, baseada na reciprocidade, onde um ser depende do outro para sobreviver. Através de rituais são estabelecidas alianças entre todos estes seres. O que significa que não respeitar um determinado ser pode causar danos as relações com muitos outros. Assim, os Mbyá-Guarani devem respeitar inclusive os seres que não lhes são diretamente uteis.

Pelo exposto, conclui-se que os Mbyá-Guarani possuem uma consciência ecológica (categoria nossa) muito apurada. Eles precisam preservar o meio ambiente para manter as relações cosmológicas necessárias para a sua sobrevivência. Da natureza só se tira o extremamente necessário, depois de obterem autorização dos seres que controlam essa "natureza". E, óbvio, isso também se aplica para a pesca. Cada espécie de peixe tem o seu já. Para obter sucesso na pesca é preciso realizar rituais prévios. Não se deve pescar mais do que se pode consumir. E deve-se respeitar também os outros seres que são aliados dos já dos peixes - o que poderíamos entender como a preservação de rios e lagos.

Porém, os cuidados rituais e de consumo que envolvem os peixes e as pescarias são mais brandas do que os cuidados

\footnotetext{
${ }^{11}$ Mantenho aqui os termos utilizados pela autora da obra consulta. Mas, é importante observar que a abordagem "mágico-religiosa" já está em desuso na Antropologia desde o século passado. Em seu lugar, atualmente, a literatura etnológica tem preferido o uso de "sistema xamânico-cosmológico".

12 O castigo ao caçador não deixa de ser também um castigo para toda a comunidade, posto que as regras alimentares do grupo impõem que todo animal abatido deve ser distribuído entre os membros da aldeia.
}

TEMPASS, Mártin César. Quanto mais peixe, melhor: sobre a importância da pesca para os Mbyá-Guarani. In: Cadernos do Lepaarq, v. XVI, n.32., p. 169-179, Jul-Dez. 2019 
necessários na caça. O que, como já observado, torna a pesca uma atividade “despreocupada". "Despreocupada”, mas regrada. E realizada com responsabilidade e respeito.

Essas regras, segundo os Mbyá-Guarani, são muito mais eficientes que as legislações ambientais oficiais ${ }^{13}$, que não dão conta da preservação necessária. Conforme os Mbyá-Guarani me afirmaram diversas vezes, os juruá, com suas leis falhas, são os únicos responsáveis pela degradação do meio ambiente. Autorizam grandes embarcações pesqueiras a retirarem toneladas de peixe das águas ao mesmo tempo que proíbem o pescador amador com sua linha e anzol de obter o seu alimento. Os Mbyá-Guarani consideram isso "uma baita burrice". Eu também considero.

Por fim, é preciso observar o texto aqui apresentado foi produzido a partir de etnografias realizadas em contextos de tensões, desde 2004 até o presente. Tensões diversas: passado versus presente, ideal versus real, discurso versus prática, estático versus dinâmico, tradição versus inovação, Mbyá-Guarani versus resto do mundo... e assim por diante. Ocorre que em seus discursos eles lembram e louvam um modo de vida e uma visão de mundo de um passado "bom", mas que hoje em dia não é mais possível porque foram confinados em pequenas áreas pelos brancos. Alguns dizem que isso é um problema momentâneo e que assim que retomarem as suas terras tradicionais tudo voltará a ser como era antes. Outros já dizem que é um caminho sem volta. O certo é que, aconteça o que acontecer, eles continuam e continuarão sendo Mbyá-Guarani, orgulhosos de sua cultura e das suas habilidades pesqueiras. Onde tem Mbyá-Guarani, tem peixe.

\footnotetext{
${ }^{13}$ Como observou Kliauga (1984) em pesquisa entre a população rural da Argentina, nas regiões do Paraná Médio e de Entre Rios, a crença no “Señor de los animales" faz com que a população em geral não cace e pesque de forma indiscriminada. E o interessante é que esta população não segue os preceitos da legislação ambiental oficial, muito mais branda e pouco fiscalizada. Eles seguem a risca as determinações tradicionais, do senhor dos animais, que pune sem exceção. Torres, Santoni e Romero (2007) também observam que os Wichí não podem pescar porque eles não possuem “guía” (licença de pesca/ "carteirinha" de pescador). E destacam que estes indígenas não compreendem porque precisam pedir permissão para o governo se quem cuida dos animais é o "dueño del monte", e junto ao qual os Wichí constumam obter autorizações para caçar, pescar e coletar.
} 


\section{REFERÊNCIAS}

ARENAS, Pastor. Etnografia y alimentación entre los Toba-Ñachilamole\#eky Wichi-Lhuku'tas del Chaco Central: Argentina. Buenos Aires: Pastor Arenas, 2003. 562p.

CADOGAN, León. Ayvu rapyta: textos míticos de los Mbyá-Guaraní del Guairá. Assunção: Fundación León Cadogan, 1997.

CLASTRES, Hélène. Terra sem mal: o profetismo tupi-guarani. São Paulo: Brasiliense, 1978.

COLOMBRES, Adolfo. Los guaranies. Buenos Aires: Del Sol, 2008.

DESCOLA, Philippe. Estrutura ou sentimento: a relação com o animal na Amazônia. Revista Mana, Rio de Janeiro, v. 4, n. 1, p. 23-45, abr. 1998.

ENRIZ, Noelia. Jeroky Poña: juegos, saberes y experiências infantiles mbyá-guaraní en Misiones. 2010. 274f. Tese (Doutorado em Antropologia Social) - Universidad de Buenos Aires, 2010.

FERREIRA, Luciane Ouriques. Mba'e achy: a concepção cosmológica da doença entre os mbyá guarani num contexto de relações interétnicas - RS. 2001. 159 f. Dissertação (Mestrado em Antropologia Social) - PPGAS, UFRGS, Porto Alegre, RS, 2001.

KLIAUGA, Catalina Saugy de. Aspectos sociales de la pesca en el Paraná Medio, Entre Rios, Argentina. In: BRACHT, Federico Guillermo (Org). Cultura tradicional del área del Paraná Médio. Buenos Aires: Instituto Nacional de Antropologia, 1984. p. 21-47.

LADEIRA, Maria Inês; MATTA, Priscila. Terras Guarani no Litoral: as matas que foram reveladas aos nossos antigos avós =Ka'agüy oreramói kuéry ojou rive vaekue $\sim$ y. São Paulo: CTI, 2004.

MARTINEZ-CROVETTO, Raúl. La alimentación entre los índios guaraníes de misiones (Republica Argentina). Etnobiologica, Corrientes, n. 4, p. 1-24, fev. 1968.

MELIÀ, Bartomeu. El Guarani conquistado y reducido. Assunção: Universidade Católica, 1986.

. A experiência religiosa guarani. In: MARZAL, Manuel M. O rosto índio de Deus. São Paulo: Vozes, 1989. Tomo I.

PALERMO, Miguel Angel; HOYOS, María de; CHIAPPE, Aldo. Guaranies: gente americana. Buenos Aires: A-Z, 2006.

PISSOLATO, Elizabeth. A duração da pessoa: mobilidade, parentesco e xamanismo mbya (guarani). São Paulo: UNESP/ ISA; Rio de Janeiro:NuTI, 2007.

POZZEBON, Altair. O direito humano à alimentação adequada na aldeia guarani de Coxilha da Cruz - Barra do Ribeiro RS. Monografia (Especialização em Direitos Humanos) - IFCH, ESMPU/UFGRS, Porto Alegre, RS, 2008.

SOUZA, José Otávio Catafesto de. Territórios e povos originários (des)velados na metrópole de Porto Alegre. In: Prefeitura Municipal de Porto Alegre; Secretaria Municipal de Direitos Humanos e Segurança Urbana. Povos Indígenas na Bacia Hidrográfica do Lago Guaíba, Porto Alegre, Rio Grande do Sul, Brasil. Porto Alegre: Prefeitura de Porto Alegre, 2008. p. 14-24.

SUSNIK, Branislava. Guerra, transito, subsistência: âmbito americano. Asunción: Litocolor, 1990.

TEMPASS, Mártin César. Orerémbiú: a relação das práticas alimentares e seus significados com a identidade étnica e a cosmologia Mbyá-Guarani. Dissertação (Mestrado em Antropologia Social) - PPGAS, UFRGS, Porto Alegre, RS, 2005.

- A culinária indígena como elo de passagem da "cultura" para a "natureza": invertendo Lévi-Strauss. Espaço Ameríndio, Porto Alegre, v. 5, n. 1, p. 69-101, jan./jun. 2011. Disponível em: http://seer.ufrgs.br/EspacoAmerindio/ article/view/20874/12089 . Acesso em: $31 \mathrm{dez} .2013$.

. A doce cosmologia Mbyá-Guarani: uma etnografia de saberes e sabores. Curitiba: Appris, 2012.

TORRES, Graciela F.; SANTONI, Mirta E.; ROMERO, Liliana N. Los wichi del Chaco Salteño ayer y hoy: alimentacíon y nutrición, 2007.

VIVEIROS DE CASTRO, Eduardo. A incostância da alma selvagem: e outros ensaios de antropologia. São Paulo: Cosac Naify, 2002. 